\title{
Octapeptide repeat insertions in the prion protein gene and early onset dementia
}

\author{
E A Croes, J Theuns, J J Houwing-Duistermaat, B Dermaut, K Sleegers, G Roks, M Van den Broeck, \\ B van Harten, J C van Swieten, M Cruts, C Van Broeckhoven, C M van Duijn
}

Objectives: The most common familial early onset dementia mutations are found in the genes involved in Alzheimer's disease; the amyloid precursor protein (APP) and the presenilin 1 and 2 (PSEN1 and 2) genes; the prion protein gene (PRNP) may be involved.

Methods: Following identification of a two-octapeptide repeat insertion in PRNP, we conducted a meta-analysis to investigate the relation of number of PRNP octapeptide repeats with age at disease onset and duration of illness; identifying 55 patients with PRNP octapeptide repeat insertions. We used a linear mixed effects model to assess the relation of number of repeats with age at disease onset, and studied the effect of the number of inserted octapeptide repeats on disease duration with a Cox proportional hazards regression analysis.

Results: We found an increasing number of repeats associated with younger age at onset $(p<0.001)$. Duration of the disease decreased significantly with the length of the octapeptide repeat $(p<0.001)$ when adjusting for age at onset.

Conclusions: Our findings show significant inverse associations of the length of the PRNP octapeptide repeat with age at disease onset and disease duration in the spongiform encephalopathies.

S everal genes are known in familial early onset dementias. The most common mutations are found in the genes involved in Alzheimer's disease. This concerns mutations in the amyloid precursor protein (APP) and the presenilin 1 and 2 (PSENI and 2) genes. Further, mutations in the prion protein gene (PRNP) may be common in early onset dementia. ${ }^{1}$ Mutations in PRNP may lead to different clinical phenotypes, including familial Creutzfeldt-Jakob disease (CJD), Gerstmann-Sträussler-Scheinker disease (GSS), and fatal familial insomnia. ${ }^{2-5}$ These mutations can be missense mutations, deletions, or insertions. ${ }^{67}$ Insertions are only found in the octapeptide repeat region located between codons 51 and 91 of PRNP, which normally contains one nonapeptide and four octapeptide repeats. ${ }^{8}$ The insertions identified so far comprised one, two, and four to nine extra octapeptide repeats. ${ }^{9}$ Expansion of an octapeptide repeat or 24-nucleotide repeat region is rare, but expansion of trinucleotide repeats are found in other neurodegenerative disorders, including Huntington's disease and the spinal cerebellar ataxias. ${ }^{10-12}$ The expansion of the polyglutamine tract in these disorders is associated with accumulation and higher toxicity of the protein. ${ }^{13}$ For several disorders with an expanded polyglutamine repeat an inverse correlation was found between repeat length and age at onset. ${ }^{14}{ }^{15}$ The relation between the numbers of octapeptide repeats and onset of disease in human spongiform encephalopathies has not been studied.

We sequenced the coding region of APP, PSEN1, PSEN2, and PRNP in a population based sample of 17 patients with early onset dementia and identified in one patient an insertion of two-octapeptide repeats. We present a metaanalysis in which we studied the relation of the number of inserted repeats with age at onset and duration of disease in all patients with PRNP octapeptide repeat insertions reported in the literature to date.

\section{METHODS}

Since 1998 we have been studying patients with early onset dementia in a defined geographical region in the northern part of The Netherlands. A medical doctor visited the patients and a member of the research team and a neurologist, using a standardised protocol based on the DSM III-R criteria, independently confirmed the diagnosis of dementia. ${ }^{16}$ After obtaining written informed consent from a relative, blood was drawn for DNA collection. In this study, 17 patients with early onset dementia were extensively studied for mutations in genes known to be involved in dementia. Exons 16 and 17 of the APP gene, and exons 3-12 of the PSEN1 and 2 genes were analysed by direct sequencing. ${ }^{17}$ The single coding exon (exon 2) of PRNP was analysed by direct sequencing of three overlapping PCR fragments $(\mathrm{A}, \mathrm{B}$, and $\mathrm{C})$ spanning the coding region. ${ }^{18}$ In one patient, visualisation of the PCR fragments on a $1.5 \%$ agarose gel stained with ethidium bromide demonstrated an insertion as an extra band of about $100 \mathrm{bp}$. To further characterise the insertion we cloned the PCR fragments in the pCR4-TOPO vector (Invitrogen, Carlsbad CA). Clones carrying the insertion were selected by colony PCR and the insert was sequenced using vector primers.

\section{Meta-analysis}

We used a Medline search with a combination of the words "mutation", "insertion", "octapeptide", or "repeats", and "prion", "PRNP", "Creutzfeldt-Jakob disease", "GerstmannSträussler-Scheinker disease", or "spongiform encephalopathy" to identify all patients with octapeptide repeat insertions in the PRNP gene. We included patients suspected of a prion disease with an octapeptide repeat extension disclosed by DNA analysis, patients with postmortem examination supporting the diagnosis of spongiform encephalopathy and a relative with an octapeptide repeat insertion, and patients with both postmortem examination and DNA analysis. Patients from PRNP insertion families

Abbreviations: APP, amyloid precursor protein; CJD, CreutzfeldtJakob disease; GSS, Gerstmann-Sträussler-Scheinker disease; PRNP, prion protein gene; PSEN1 and 2, presenilin 1 and 2; REML, restricted maximum likelihood 
suffering from an unidentified neurodegenerative disease, without PRNP analysis or postmortem examination, were not included.

For statistical analyses, we used the log transformed age at onset to obtain a normally distributed outcome. A linear mixed effects model fitted by restricted maximum likelihood (REML) was used to assess the relation between number of inserted octapeptide repeats and age at disease onset, and to estimate the part of the between family variance of age at onset explained by PRNP codon 129 and number of inserted octapeptide repeats. Analyses were performed adjusted and unadjusted for the PRNP codon 129 genotype. To study the effect of the number of inserted octapeptide repeats on disease duration we performed a Cox proportional hazards regression analysis, adjusted for age at onset. PRNP codon 129 was not included in this model because of the limited number of independent observations. Because we observed an outlier in the first 6 months, analyses were performed by conditioning on surviving the first 6 months. Robust standard errors were used that take into account dependence of the data.

\section{RESULTS}

\section{Mutation screening and clinical phenotype}

In this sample of 17 patients with early onset dementia, we found two mutations in genes known to be involved in dementia. Firstly, we observed a single base change predicting an amino acid change at codon 301 (T301M) in the PSEN2 gene. The patient carrying this mutation experienced a lack in short and long term memory just after 60 years of age. Within a couple of years the condition of the patient deteriorated and the patient died more than 10 years after onset of the symptoms, with the clinical diagnosis of Alzheimer's dementia. The family history revealed early and late onset dementia of unknown type in several family members. However, in the cell transfection experiments there is no evidence up until now that this PSEN2 mutation is functional. The $\beta$ amyloid $42 / 40$ ratio was not altered in cells carrying the T301M mutation compared to cells carrying the wild type allele. Although this does not exclude the possibility that the mutation is functional, it is unlikely, as all functional PSEN 1 and 2 mutations known to date have an effect on the $\beta$ amyloid $42 / 40$ ratio.

The second mutation found was a two-octapeptide repeat insert in the PRNP gene. The patient carrying this mutation developed an atypical dementia, the age of first symptoms being in the late 50s. In the following 10 years, the condition of the patient slowly deteriorated into a mute state. Myoclonus, cerebellar, and visual disturbances were absent. Electroencephalography did not show the periodic sharp wave complexes typical for CJD. Atypical dementia of late onset was reported in one first degree relative.

The octapeptide repeat insertion in PRNP contained an identical double repeated 24-nucleotide sequence located between the fourth (normally R3) and fifth (R4) repeat and included a silent nucleotide substitution from GGG to GGA in the seventh triplet (coding for glycine in both cases). The nucleotide sequence of this octapeptide repeat insertion has been designated R2a. ${ }^{19}$ The nucleotide sequence in the third and fourth octapeptide repeat in our patient also changed, and was identical to that described by van Harten et al in a patient of Dutch origin (R1 R2 R2a R2 R2a R2a R4). ${ }^{20}$ The normal order is R1 (the nonapeptide repeat) R2 R2 R3 R4. The patient was heterozygous for the polymorphic PRNP codon 129, carrying the valine (V) allele on the chromosome with the octapeptide repeat insertion, which is identical to the disease haplotype in the patient described by Van Harten..$^{20}$
Genealogical data from our patient and the patient described by Van Harten et al were collected using the municipal registers. We were able to trace back the ancestors of both patients for six generations, until 1780, but it was not possible to link both patients to a common ancestor within these six generations. Genealogical data were complete, except for one branch in the fifth generation of the patient described here, for which no information was available. The dead end in one branch in the fifth generation, nonpaternity, or a common ancestor before 1780 may explain our failure to establish a genealogical link.

\section{Meta-analysis of studies of PRNP octapeptide repeat insertions}

Twenty four articles reporting PRNP octapeptide repeat insertions in 22 different families were identified. ${ }^{8} 9^{19-40}$ In total 55 patients fulfilled our inclusion criteria and had sufficient information on clinical characteristics. Key clinical features were a progressive dementia, ataxia, or other cerebellar disturbances, and abnormal behaviour, mood disorders, or other psychiatric symptoms. Table 1 shows the age at onset, disease duration and PRNP codon 129 genotype as described in the papers. Fig 1 gives the findings of the meta-analysis on the association between the number of inserted octapeptide repeats and the age at disease onset. In this analysis, 38 patients from 17 families with information on the PRNP codon 129 genotype were included. We found a significant inverse relation between the number of inserted octapeptide repeats in PRNP and age at disease onset $(\mathrm{p}=0.0002$ in the model unadjusted for PRNP codon 129 genotype and $\mathrm{p}<0.0001$ after adjusting for this genotype). Overall, the codon 129 genotype contributed significantly to the model $(p=0.0003)$. Compared with carriers of the PRNP codon 129 genotype MV, patients with genotype MM tended to have an earlier onset and carriers of genotype VV a later onset. The PRNP codon 129 genotype and the number of inserted octapeptide repeats in PRNP explain together 93\% of the between family variance in age at onset, leaving only $7 \%$ unexplained.

The relation between number of repeats and survival after disease onset was assessed in all 55 patients. Adjusted for age at onset, survival was significantly prolonged in carriers of the shorter repeats $(\mathrm{p}<0.001)$.

Finally, we extended the analyses to affected family members $(n=40)$ of confirmed cases, who were suspected to carry a PRNP insert mutation on clinical grounds, but for whom genetic analysis or a neuropathological confirmation of CJD or GSS were not available. In this analysis, the relation between number of PRNP repeats and age at onset remained statistically significant $(\mathrm{p}<0.001)$. However, the relation between number of PRNP repeats and survival was no longer significant.

\section{DISCUSSION}

In this study of 17 patients with early onset dementia we identified two carriers of mutations in genes known to be involved in presenile dementia. One of the mutations, the PSEN2 T301M mutation, is unlikely to be a causal mutation given the absence of an effect on the $\beta$ amyloid 42/40 levels in cells transfected with the mutation. Further, we detected a mutation in PRNP in one of 17 patients with early onset dementia. The PRNP two-octapeptide repeat insertion we observed in this patient led to an atypical form of dementia with disease duration of more than 10 years. Repeat insertions of two extra octapeptide repeats have been described previously. ${ }^{19} 20$ Van Harten et al also described a patient with a two-octapeptide repeat insertion with atypical dementia in The Netherlands. ${ }^{20}$ We could not find a link between the two Dutch patients within six generations. 
Table 1 Age at disease onset, disease duration, and PRNP codon 129 genotype in patients with PRNP octapeptide repeat insertions

\begin{tabular}{|c|c|c|c|c|c|}
\hline Article & n Repeats & n Patients* & $\begin{array}{l}\text { PRNP codon } \\
129 \dagger\end{array}$ & $\begin{array}{l}\text { Age at onset } \\
\text { (years) }\end{array}$ & $\begin{array}{l}\text { Disease duration } \\
\text { (months) } \ddagger\end{array}$ \\
\hline Laplanche $^{29}$ & 1 & 1 & $M M$ & 73 & 4 \\
\hline Goldfarb $^{19}$ & 2 & 2 & MM & $58 / 75$ & $3 / 156+$ \\
\hline Van Harten ${ }^{20}$ & 2 & 1 & W & 61 & 84 \\
\hline This article & 2 & 1 & MV & 59 & $120+$ \\
\hline Laplanche $^{29}$ & 4 & 1 & $\mathrm{~V} V$ & 82 & 4 \\
\hline Rossi ${ }^{36}$ & 4 & 1 & MM & 65 & 6 \\
\hline Campbell $^{21}$ & 4 & 1 & MM & 56 & 2 \\
\hline Yanagihara ${ }^{9}$ & 4 & 1 & MM & 56 & 5 \\
\hline Goldfarb $^{26}$ & 5 & 2 & n.a. & $31 / 45$ & $60 / 180$ \\
\hline Cochran $^{23}$ & 5 & 3 & MM & 26 to 44 & 84 to $168+$ \\
\hline Skworc ${ }^{37}$ & 5 & 3 & MV & 51 to 61 & 4 to 96 \\
\hline Oda ${ }^{33}$ & 6 & 3 & MM & 33 to 34 & 60 to $84+$ \\
\hline Capellari $^{22}$ & 6 & 2 & MV & 38 & $48 / 120$ \\
\hline Nicholl $^{32}$ & 6 & 2 & n.a. & $34 / 46$ & $3 / 60$ \\
\hline Collinge, ${ }^{24}$ Poulter $^{35}$ & 6 & 13 & $\mathrm{MM}^{8} / \mathrm{MV}^{3}$ & 22 to 47 & 24 to 156 \\
\hline Goldfarb $^{26}$ & 7 & 3 & n.a. & 23 to 35 & 120 to 156 \\
\hline Dermaut $^{40}$ & 7 & 2 & $M M$ & $24 / 31$ & 132 \\
\hline Goldfarb $^{27}$ & 8 & 3 & MM & 35 to 54 & 3 to 24 \\
\hline Laplanche $^{30}$ & 8 & 5 & MM & 21 to 32 & 36 to $144+$ \\
\hline Van Gool ${ }^{38}$ & 8 & 3 & $M V^{1} / V^{2}$ & 21 to 54 & $12+$ to 72 \\
\hline Moore, ${ }^{31}$ Xiang $^{42 \S}$ & 8 & 4 & n.a. & 23 to 41 & n.a. \\
\hline Owen ${ }^{34}$ & 9 & 1 & n.a. & 53 & 30 \\
\hline Krasemann ${ }^{28}$ & 9 & 1 & MM & 32 & $72+$ \\
\hline \multicolumn{6}{|c|}{$\begin{array}{l}\text { *Patients with mutation analysis, or patients with autopsy and a blood relative with mutation analysis, or patients } \\
\text { with mutation analysis as well as autopsy, are reported. }+M \text {, methionine; } V \text {, valine; the numbers in superscript } \\
\text { denote the number of carriers. } ¥ \text { For patients alive at time of publication, the disease duration is indicated with } \\
\text { " }+ \text { " sign. } \$ \text { Not included in the analyses because of missing age at onset and duration for each patient. n.a., no } \\
\text { available. }\end{array}$} \\
\hline
\end{tabular}

However, the rarity of the PRNP insertion mutations, the presence of the $\mathrm{V}$ allele on the PRNP insertion haplotype, and particularly the identical nucleotide sequence of the inserted octapeptide repeats in both patients, suggest that the patients are related and developed the disease as a result of the same mutation.

Goldfarb et al described the second patient. ${ }^{19}$ This young patient ( 58 years) showed a severe neurological deterioration leading to mutism and comatose state within weeks. However, the mother of the patient, carrying the same mutation, showed a gradual cognitive decline at the age of 75 years leading to mutism 13 years later. ${ }^{19}$ Also, in the family described by us there is a major difference in onset age between the patient (late 50s) and the first degree relative (late 70s). In the spongiform encephalopathies, the stability

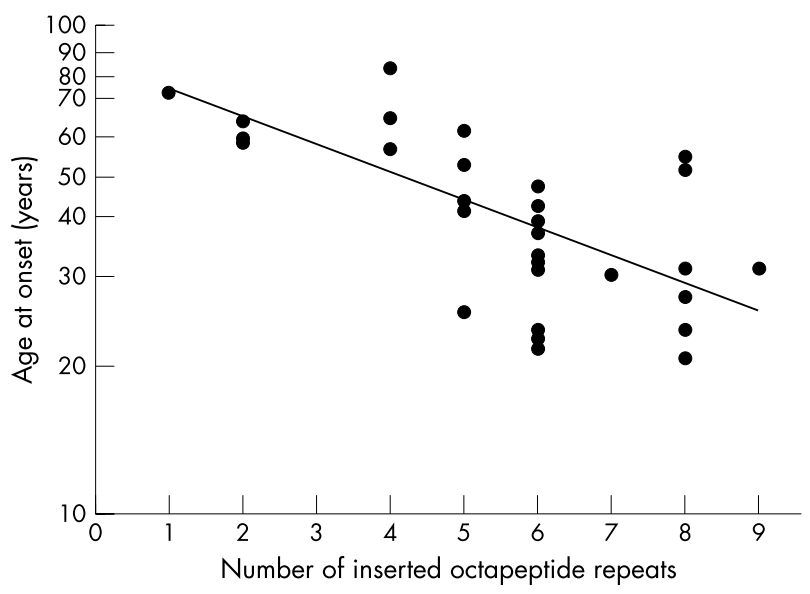

Figure 1 Relation between the number of insertions in the PRNP octapeptide region and age at onset (on a log scale), adjusted for PRNP codon 129 genotype. The best fit line is shown. of the octapeptide repeat insertions found in PRNP was shown to be high in several generations, suggesting that a difference in length of the inserted octapeptide repeat may not explain the difference in onset age between first degree relatives. ${ }^{34}$ This suggests that the disease penetrance is highly variable and that other factors than the mutation itself may determine the onset and progression of the disease, even in a single family. Also the clinical features of the PRNP insert mutations show a wide variability and range from the typical CJD phenotype to GSS or even other neurodegenerative disorders such as Huntington's disease. The phenotypic heterogeneity and late onset in some carriers may explain also why the family history appears negative in a considerable number of patients. If the disease may express as late as age 75 years, carriers may already have died of other disorders, particularly in past centuries.

The discordance in age at onset between families of patients carrying PRNP octapeptide repeat insertions prompted us to perform a meta-analysis to examine the relation between number of inserted octapeptide repeats in PRNP and age at disease onset. Despite the large differences found in families, we found a significant inverse relation between number of inserted octapeptide repeats and age at disease onset. The model including octapeptide repeat length and PRNP codon 129 genotype explained about 93\% of the variance observed in the age at onset between the families, leaving only $7 \%$ of the total variance unexplained, which may either be caused by genetic or shared environmental factors, or by random error. The meta-analysis also shows that the 10 year disease duration in our patient with two extra octapeptide repeats is exceptional. However, the decreased survival which is observed in carriers of shorter octapeptide repeat insertions is, to a large extent, attributable to the older age at onset. In the analyses taking into account the age at onset, we found a significantly prolonged survival associated with the shorter repeats. The duration of illness in our patient is also compatible with the findings of Van Harten et al, who described a disease duration of 7 years. ${ }^{20}$ 
Animal studies have shown that prion protein molecules containing a larger octapeptide repeat region aggregate more readily and have a higher protease resistance..$^{41}$ In line with these findings, our study suggests that longer insertions in the octapeptide repeat region in PRNP may lead to the inhibition of turnover resulting in a faster accumulation of the protein, earlier onset of disease, and reduced survival.

In conclusion, in a Dutch population-based sample of 17 patients with early onset dementia, we identified one patient in whom the disease was most likely explained by a twooctapeptide repeat insertion in PRNP. We further showed in a meta-analysis that the number of inserted octapeptide repeats in PRNP is inversely related to age at onset and duration of disease. Our meta-analysis shows that the length of the octapeptide repeat insertion in combination with the PRNP codon 129 genotype explains a large part of the variation in age at onset observed. The challenge in the future will be to determine the biological mechanism underlying this process.

\section{ACKNOWLEDGEMENTS}

We thank Mrs Hilda Kornman and Mr W. Pasveer for collection of the genealogy data. This work was supported by the Dutch Ministry of Health, Welfare and Sports (VWS), the Netherlands Organisation for Scientific Research (NWO), and a EU grant (CT98-7022); the Fund for Scientific Research Flanders (FWO-V), InterUniversity Attraction Poles (IUAP) programme P5/19 of the Belgian Federal Science Policy Office, the Medical Foundation Queen Elisabeth (GSKE), the International Alzheimer Research Foundation (IARF) and the Special Research Fund of the University of Antwerp (UIA), Belgium. Jessie Theuns and Marc Cruts are postdoctoral fellows of the FWO-F.

\section{Authors' affiliations \\ E A Croes, J J Houwing-Duistermaat, K Sleegers, G Roks, C M van Duijn, Department of Epidemiology \& Biostatistics, Erasmus MC, Rotterdam, The Netherlands}

J Theuns, B Dermaut, M Van den Broeck, M Cruts, C Van Broeckhoven

C M van Duijn, Department of Molecular Genetics, Flanders Interuniversity Institute for Biotechnology (VIB8), University of Antwerp (UIA), Antwerpen, Belgium

B van Harten, Department of Neurology, Sint Lucas Andreas Hospital, Amsterdam, The Netherlands

J C van Swieten, Department of Neurology, Erasmus MC, Rotterdam, The Netherlands

Competing interests: none declared

Correspondence to: C M van Duijn, Department of Epidemiology \& Biostatistics, Erasmus MC, PO Box 1738, 3000 DR Rotterdam, The Netherlands; c.vanduijn@erasmusmc.nl

Received 5 June 2003

In revised form 3 November 2003

Accepted 8 November 2003

\section{REFERENCES}

1 Finckh U, Muller-Thomsen T, Mann U, et al. High prevalence of pathogenic mutations in patients with early-onset dementia detected by sequence analyses of four different genes. Am J Hum Genet 2000:66:110-17.

2 Boellaard JW, Brown P, Tateishi J. Gerstmann-Straussler-Scheinker disease-the dilemma of molecular and clinical correlations. Clin Neuropathol 1999; 18:271-85

3 Collins S, McLean CA, Masters CL. Gerstmann-Straussler-Scheinker syndrome, fatal familial insomnia, and kuru: a review of these less common human transmissible spongiform encephalopathies. J Clin Neurosci $2001 ; 8: 387-97$.

4 Harder A, Jendroska K, Kreuz F, et al. Novel twelve-generation kindred of fatal familial insomnia from Germany representing the entire spectrum of disease expression. Am J Med Genet 1999;87:311-16.

5 Monari L, Chen SG, Brown P, et al. Fatal familial insomnia and familial Creutzfeldt-Jakob disease: different prion proteins determined by a DNA polymorphism. Proc Natl Acad Sci USA 1994;91:2839-42.

6 Palmer MS, Collinge J. Mutations and polymorphisms in the prion protein gene. Hum Mutat 1993;2:168-73.
7 Beck JA, Mead S, Campbell TA, et al. Two-octapeptide repeat deletion of prion protein associated with rapidly progressive dementia. Neurology 2001;57:354-6.

8 Owen $F$, Poulter $M$, Shah $T$, et al. An in-frame insertion in the prion protein gene in familial Creutzfeldt-Jakob disease. Brain Res Mol Brain Res 1990;7:273-6

9 Yanagihara C, Yasuda M, Maeda K, et al. Rapidly progressive dementia syndrome associated with a novel four extra repeat mutation in the prion protein gene. J Neurol Neurosurg Psychiatry 2002;72:788-91.

10 Stevanin G, Durr A, Brice A. Clinical and molecular advances in autosomal dominant cerebellar ataxias: from genotype to phenotype and physiopathology. Eur J Hum Genet 2000;8:4-18.

11 Davies S, Ramsden DB. Huntington's disease. Mol Pathol 2001;54:409-13.

12 Masino L, Pastore A. A structural approach to trinucleotide expansion diseases. Brain Res Bull 2001;56:183-9.

13 Sisodia SS. Nuclear inclusions in glutamine repeat disorders: are they pernicious, coincidental, or beneficial? Cell 1998;95:1-4.

14 Squitieri F, Sabbadini G, Mandich P, et al. Family and molecular data for a fine analysis of age at onset in Huntington disease. Am J Med Genet 2000;95:366-73.

15 Andrew SE, Goldberg YP, Kremer B, et al. The relationship between trinucleotide (CAG) repeat length and clinical features of Huntington's disease. Nat Genet 1993:4:398-403.

16 American Psychiatric Association. Diagnostic and statistical manual of mental disorders, 3rd edn, revised. Washington DC: American Psychiatric Association, 1987.

17 Cruts $M$, van Duijn $C M$, Backhovens $H$, et al. Estimation of the genetic contribution of presenilin-1 and -2 mutations in a population-based study of presenile Alzheimer disease. Hum Mol Genet 1998;7:43-51

18 Van Everbroeck B, Croes EA, Pals P, et al. Influence of the prion protein and the apolipoprotein $\mathrm{E}$ genotype on the Creutzfeldt-Jakob disease phenotype. Neurosci Lett 2001;313:69-72.

19 Goldfarb LG, Brown P, Little BW, et al. A new (two-repeat) octapeptide coding insert mutation in Creutzfeldt-Jakob disease. Neurology 1993;43:2392-4.

20 Van Harten B, van Gool WA, Van Langen IM, et al. A new mutation in the prion protein gene: a patient with dementia and white matter changes. Neurology 2000:55:1055-7.

21 Campbell TA, Palmer MS, Will RG, et al. A prion disease with a novel 96base pair insertional mutation in the prion protein gene. Neurology 1996:46:761-6.

22 Capellari S, Vital C, Parchi P, et al. Familial prion disease with a novel 144-bp insertion in the prion protein gene in a Basque family. Neurology 1997;49:133-41

23 Cochran EJ, Bennett DA, Cervenakova L, et al. Familial Creutzfeldt-Jakob disease with a five-repeat octapeptide insert mutation. Neurology 1996;47:727-33.

24 Collinge J, Brown J, Hardy J, et al. Inherited prion disease with 144 base pair gene insertion. 2. Clinical and pathological features. Brain 1992;115:687-710.

25 Duchen LW, Poulter M, Harding AE. Dementia associated with a 216 base pair insertion in the prion protein gene. Clinical and neuropathological features. Brain 1993; 1 16:555-67.

26 Goldfarb LG, Brown P, McCombie WR, et al. Transmissible familial Creutzfeldt-Jakob disease associated with five, seven, and eight extra octapeptide coding repeats in the PRNP gene. Proc Natl Acad Sci USA 1991;88:10926-30.

27 Goldfarb LG, Brown P, Vrbovska A, et al. An insert mutation in the chromosome 20 amyloid precursor gene in a Gerstmann-StrausslerScheinker family. J Neurol Sci 1992;111:189-94.

28 Krasemann S, Zerr I, Weber T, et al. Prion disease associated with a novel nine octapeptide repeat insertion in the PRNP gene. Brain Res Mol Brain Res 1995:34:173-6.

29 Laplanche JL, Delasnerie-Laupretre N, Brandel JP, et al. Two novel insertions in the prion protein gene in patients with late-onset dementia. Hum Mol Genet 1995:4:1109-11.

30 Laplanche JL, Hachimi KH, Durieux I, et al. Prominent psychiatric features and early onset in an inherited prion disease with a new insertional mutation in the prion protein gene. Brain 1999; 122:2375-86.

31 Moore RC, Xiang F, Monaghan J, et al. Huntington disease phenocopy is a familial prion disease. Am J Hum Genet 2001;69:1385-8.

32 Nicholl D, Windl O, de Silva R, et al. Inherited Creutzfeldt-Jakob disease in a British family associated with a novel 144 base pair insertion of the prion protein gene. J Neurol Neurosurg Psychiatry 1995;58:65-9.

33 Oda T, Kitamoto T, Tateishi J, et al. Prion disease with 144 base pair insertion in a Japanese family line. Acta Neuropathol 1995;90:80-6.

34 Owen F, Poulter M, Collinge J, et al. A dementing illness associated with a novel insertion in the prion protein gene. Brain Res Mol Brain Res 1992;13:155-7.

35 Poulter M, Baker HF, Frith CD, et al. Inherited prion disease with 144 base pair gene insertion. 1. Genealogical and molecular studies. Brain 1992;115:675-85.

36 Rossi G, Giaccone G, Giampaolo L, et al. Creutzfeldt-Jakob disease with a novel four extra-repeat insertional mutation in the PrP gene. Neurology 2000;55:405-10. 
37 Skworc KH, Windl O, Schulz-Schaeffer WJ, et al. Familial Creutzfeldt-Jakob disease with a novel 120-bp insertion in the prion protein gene. Ann Neurol 1999;46:693-700.

38 Van Gool WA, Hensels GW, Hoogerwaard EM, et al. Hypokinesia and presenile dementia in a Dutch family with a novel insertion in the prion protein gene. Brain 1995;118:1565-71.

39 Owen F, Poulter $M$, Lofthouse $R$, et al. Insertion in prion protein gene in familial Creutzfeldt-Jakob disease. Lancet 1989;i:51-2.
40 Dermaut B, Cruts $M$, Backhovens $\mathrm{H}$, et al. Familial Creutzfeldt-Jakob disease in a patient carrying both a presenilin 1 missense substitution and a prion protein gene insertion. J Neurol 2000;247:364-8.

41 Priola SA, Chesebro B. Abnormal properties of prion protein with insertional mutations in different cell types. J Biol Chem 1998;273:11980-5.

42 Xiang $F$, Almqvist EW, Huq M, et al. A Huntington disease-like neurodegenerative disorder maps to chromosome 20p. Am J Hum Genet 1998;63:1431-8.

\section{NEUROLOGICAL PICTURE}

Unusual differential diagnosis of leptomeningeal enhancement: moyamoya disease

W e report on a 13 year old boy who presented with a focal left sided motoric seizure and a history of progressive headaches since 6 years of age. On neurological examination, motor function of the limbs, deep tendon reflexes, and sensory examination were normal, but there was slight left sided bradydisdiadochokinesis. Routine blood tests and anti-immune antibody screening as well as cerebrospinal fluid (CSF) analysis were normal.

Magnetic resonance imaging (MRI) showed multiple curvilinear areas of high signal intensity in leptomeninges (fig lA) and diffuse enhancement along leptomeningeal surfaces (fig 1B). Digital subtraction angiography demonstrated severe stenoses of both distal internal carotid artery (ICA) segments (fig IC) as well as extensive leptomeningeal collaterals (fig 1D)

Leptomenigeal enhancement on postcontrast $\mathrm{Tl}$ weighted MR images has been reported in association with meningitis, meningeal carcinomatosis, and angiitis. Common among these diseases is pathologic inflammation or carcinomatous infiltration of the leptomeninges, with or without involvement of the small leptomeningeal vessels.

In 1995 Ohta et al reported diffuse leptomeningeal enhancement on postcontrast Tl weighted MRI in children with moyamoya disease and named these finding the "ivy-sign", because it resembles ivy creeping on stones. The ivy-sign can be found on fluid attenuation inversion recovery (FLAIR) images, as well as on contrast enhanced MRI. ${ }^{2}{ }^{3}$

The characteristic enhancement is caused by an engorged pial network via leptomeningeal anastomosis. The source of leptomeningeal high signal intensity on FLAIR images is not clear but it seems largely due to slow flowing vessels of the engorged pial network. ${ }^{2}$ Thus, the mechanism of the leptomeningeal ivy-sign can be explained by an engorged pial network and possibly the congested meninges.

J Gaa, S Weidauer

Institute of Neuroradiology, Klinikum der Johann Wolfgang Goethe-Universität Frankfurt,

Germany

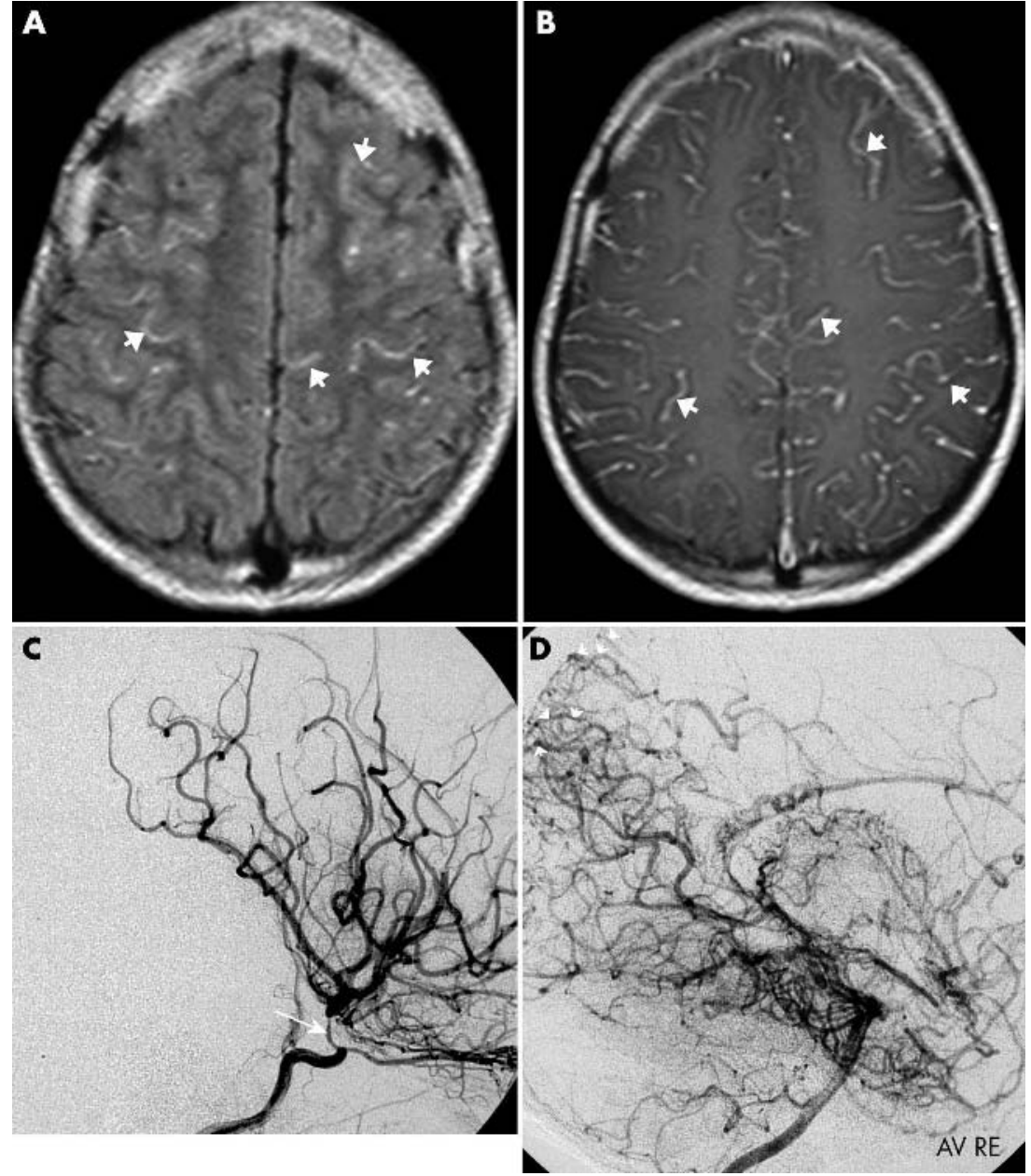

Figure 1 (A) Axial FLAIR MRI reveals multiple areas of high signal intensity (arrows) in leptomeninges. (B) Axial contrast enhanced T1 weighted image shows diffuse enhancement along leptomeningeal surfaces (arrows). (C) Lateral view of right carotid angiogram and (D) right vertebral angiogram demonstrate severe stenoses at the distal ICA (arrow) and wide terminal segments of the posterior and middle cerebral arteries due to extensive leptomeningeal collateral flow (arrowheads).

Correspondence to: Dr J Gaa, Department of Neuroradiology, University of Frankfurt, Schleusenweg 2-16, 60528 Frankfurt, Germany; jochen.gaa@kgu.de

\section{References}

1 Ohta T, Tanaka H, Kuroiwa T. Diffuse leptomeningeal enhancement, "ivy sign", in magnetic resonance images of moaymoya disease in childhood: case report. Neurosurg 1995:37:1009-12.

2 Maeda M, Tsuchida C. "Ivy-sign" on fluidattenuated inversion recovery images in childhood moyamoya disease. American Journal of Neuroradiology 1999;20:1836-38.

3 Yoon HK, Shin HJ, Chang YW. "Ivy sign" in childhood moyamoya disease: depiction on FLAIR and contrast-enhanced T1weighted MR images. Radiology 2002;223:384-89. 